\title{
LIRISMO E CONSERVADORISMO NA ARENA POLÍTICA: O CONTO "SHIVÁ, BRINCANDO..." DA ESCRI- TORA GOESA MARIA ELSA DA ROCHA
}

\author{
Hélder Garmes (Universidade de São Paulo) \\ Paul Melo e Castro (University of Leeds)
}

\begin{abstract}
RESUMO
O presente artigo faz uma breve interpretação do conto "Shivá, brincando..." (1963), da escritora goesa Maria Elsa da Rocha (1923-2005), tendo por referência o contexto histórico de sua publicação, isto é, o momento que se seguiu ao fim do período colonial português e a subseqüente integração de Goa à República da Índia. Marcado pela crescente presença de movimentos exigindo uma partilha mais justa da terra agrícola, o conto, de viés subjetivista, questiona o motivo de tais reivindicações e se coloca ao lado da manutenção da ordem social tradicional goesa.
\end{abstract}

PALAVRAS-CHAVE: conto, literatura indo-portuguesa, literatura goesa.

\begin{abstract}
This article is a brief interpretation of the short story "Shivá, brincando..." (1963), by the Goan writer Elsa Maria da Rocha (1923-2005). In light of the historical context of its publication- the moment following the end of Portuguese colonial rule and the integration of Goa into the Republic of India - we analyse how Rocha's short narrative tackles the emergence in the territory of movements demanding a fairer division of the land. With its subjective, the story calls into question the real motives underlying such demands and defends the traditional social order of Goa.
\end{abstract}

KEYWORDS: short story, Indo-Portuguese literature, Goan literature. 
Maria Elsa da Rocha nasceu em Goa em 1923. Três anos depois, em 1926, Antonio de Oliveira Salazar ganhava pela primeira vez lugar no governo português, como Ministro das Finanças, logo renunciando. No entanto, quando, em 1928, o general Carmona assumiu o poder, Salazar foi novamente convidado para compor o governo e ocupar o mesmo ministério, agora com plenos poderes. Em 1933, criou-se o Estado Novo com Salazar à sua frente, revitalizando o projeto colonialista português. Em 1968, Marcello Caetano assume o governo no lugar de Salazar, que morre em 1970. Essa ordem política perduraria até 25 de Abril de 1974, finalizando com a Revolução dos Cravos. Nos anos de 1974 e 1975 as colônias portuguesas conquistariam suas independências. Goa, no entanto, deixara de ser portuguesa já em 1961, ainda sob o governo de Salazar, quando passara a integrar a República Indiana, criada em 1947.

Constata-se, portanto, que Maria Elsa da Rocha viveu a Goa salazarista desde o seu surgimento até a expulsão dos portugueses dali, vivenciando ainda as subsequentes transformações daquela ex-colônia portuguesa, as quais começou a retratar em curtas narrativas na imprensa local. Segundo Leopoldo da Rocha, a autora

foi professora de instrução primária durante a vida toda e última professora a ensinar o português na Escola Básica da capital de Goa, mesmo anos após a incorporação de Goa na União Indiana (sic). Deu os primeiros passos do magistério em longínquas paragens como Damão e Novas Conquistas de Goa. (ROCHA, 2010)

A partir de uma dicção que poderíamos designar de lírico-neo-realista, Maria Elsa da Rocha sempre foi muito preocupada em registrar o cotidiano do povo goês, com quem travou conhecimento através do seu trabalho. Segundo Leopoldo da Rocha, o conjunto dos seus contos trata (muitas vezes dum ponto de vista lusófono, mas defensor duma Goa indiana) do cotidiano, dos costumes, dos desejos de uma população que nunca constituiu o foco de atenção da administração colonial portuguesa.

Um poema chamado "Sâdhu", escrito dias depois de tomada de Goa pela República Indiana, mostra claramente a atitude da autora em relação ao regime anterior e à nova realidade indiana que se configurava:

Sâdhu,

Já sei porque me olhavas

Com esse olhar turvo

Das cheias do Ganges

Acaso tinha eu culpa,

Se era o que era

Qual barca vogando

No oceano da Vida?

Se vivia...

Trazendo em mim

Complexos de tendências

Adquiridas e inatas

Sob o peso asfixiante

De séculos ocidentais

Que me não deixavam em paz 
Um só momento fugaz

E que me cobriam a alma

Em avalanchas de neve

De Saudade distante?

Se, receosa...

Ia vogando sozinha,

À volta sentindo

Falésias ruins?

Não desfrutando da Vida

A essência subtil

Que aliás nos tornava

Assim tão afins?

Sâdhu?

Porque me olhavas assim?

Acaso não te lembravas

Que um Brahmane em Goa

Sob um forçado de séculos

A que o havia votado

Um mero capricho do Fado

Inda há pouco

Tinha de ser assim?...

Jai Hind!

26th Dec 1961 (ROCHA, 1962: p. 2)

É de notar aqui o realce que a autora dá a seu estatuto social de brâmane. Por mais aportuguesados que os brâmanes católicos pudessem parecer aos olhos de Îndia milenar, da perspectiva do eu-lírico, o sâdhu, ou sábio hindu, teria o dever de perceber a essência indiana de sua identidade. Se o conteúdo do poema mostra claramente o pendor político antidominação lusitana da autora, a língua empregue testemunha a presença da história colonial na formação da elite goesa. Nascida no seio de uma família de batecares (espécie de latifundiários locais) católicos, Maria Elsa da Rocha recebeu educação-bilingue, falando tanto português quanto concani (língua regional de Goa).

Como professora de português, a escritora sempre esteve ligada à língua de Eça de Queirós, mas, enquanto via o hindi, o inglês, o concani ganharem relevo na sociedade local, viu a língua portuguesa cair no ostracismo, estigmatizada como língua do colonizador. No conto "Shivá, brincando", Maria Elsa da Rocha consegue uma simbiose harmônica entre seu nacionalismo indiano, sua defesa da posição social dos brâmanes batecares, sua empatia pelas classes desfavorecidas e a língua portuguesa, veículo aqui privilegiado para expressar preocupações unicamente goesas. Maria Elsa da Rocha morreu em 2005, antes de ter conseguido realizar o lançamento de seu livro de contos Vivências partilhadas, cuja publicação ocorreu em Goa naquele mesmo ano.

O conto que iremos comentar aqui foi extraído do periódico $A$ Vida, de 23 de junho de 1963, por Vimala Devi e Manuel de Seabra, e reproduzido na antologia de textos literários goeses que acompanha a obra $A$ 
literatura indo-portuguesa (1971). Aparece também na supracitada coletânea de contos da autora. Retomemos primeiramente a sua diegese. A ação se passa no meio rural, ao final da tarde. Vatsol, uma mulher do grupo dos manducares (trabalhadores rurais ligados à terra dum batecar), pede ao barqueiro Suriá para atravessá-la à outra margem do rio. Ela quer avisar o batecar que o irmão dela, Sauló, pretendia assaltar a casa dele naquela noite. Vatsol sente uma grande lealdade para com os batecares católicos que sempre cumpriram com o seu dever ancestral de velar pelo bem-estar dos seus manducares. Além disso, ela receia que um assalto frustrado chefiado por seu irmão prejudique sem remédio a posição da sua família. Depreende-se das reações do barqueiro Suriá e de Vatsol que estão apaixonados. A jovem, angustiada com a insensatez do irmão, acaba, em meio à travessia do rio, por contar os planos do Sauló ao barqueiro. Ficamos ainda sabendo que a casa do batecar, onde medra uma enorme árvore sagrada ou pimpôll, tradicionalmente associada a Shivá, é protegida por essa divindade, o que faria com que o plano de Sauló estivesse de todos os modos fadado ao fracasso. Vatsol, com medo da noite que logo chega, desiste de ir à casa do batecar e Suriá promete que a substituirá. Leva novamente Vatsol para a margem da qual partiram e prepara-se para seguir à casa grande no lugar dela, mas acaba parando em própria habitação. Balcust, o mocadão (capataz ou feitor, em suma, o homem de confiança dos batecarás), bate à sua porta e pede-lhe para que o leve à outra margem do rio. Pretende avisar a avó de Vatsol e de Sauló que este caíra sem sentidos em frente à casa do batecar, depois de ser atacado por uma cobra gigante que saíra do pimpôll em frente à casa. Esclarecendo que o rapaz já estava bem, conta que Sauló fora ali chamado para substituí-lo como mocadão da casa. Chegara antes que qualquer um suspeitasse e já na primeira noite tinha lhe acontecido esse episódio. Conta também que ninguém entendeu quando o rapaz começou a pedir desculpas a todos os membros da família. Fica subentendido que Sauló pretendia assaltar e não vigiar a casa, mas como todos o esperavam para substituir o mocadão, acreditaram que ali estava para isso. Surpreendido pela cobra, que seria o próprio Shivá, Sauló caiu sem sentidos. Quando acordou, sem saber que fora chamado para substituir o mocadão, passou a pedir desculpas aos batecarás por seu intento criminoso. Sauló acaba por se tornar o mocadão do prédio (herdade ou fazenda, no português de Goa) e, ao final, Vatsol e Suriá se casam, sendo que Shivá limpa o céu de nuvens para iluminar o dia do casamento.

Todas as personagens do conto são goeses, e portanto etnicamente indianas. Subentende-se que os batecares são católicos (por terem uma crioula, criada em termos locais, deste credo), enquanto os seus manducares seguem o hinduísmo. O casal de protagonistas, Vatsol e Suriá, têm nomes, comportamento e se vestem à moda hindu. Vejamos Vatsol, que é melhor descrita:

Os dedos dos pés da Vatsol, com anéis de prata, agarravam, autómatos, o dorso do varado de pedações de lodo seco à desconjuntado [...] A chita cor da açafrão do saiote da Vatsol distinguia-se nítida, como um borrão de luz no declive da margem [...] E tinha os cabelos lustrosos presos num carrapito e ao colo a fiada de continhas pretas, a fiada de aliança.... (DEVI \& SEABRA, 1971, v. 2, p. 371-372).

Vatsol veste-se de amarelo açafrão, tem nos pés anéis de prata, mantém os cabelos lustrosos e presos (um hábito cultural das mulheres indianas) e traz um colar de contas pretas no pescoço, que a narrativa sugere ser o símbolo do compromisso amoroso do casal. 
Tudo se passa dentro de uma ordem social campesina profundamente arraigada na história milenar do território. A diegese tem lugar no espaço rural, onde vigora o sistema tradicional de batecarato. O princípio de direito que norteia esse sistema é o seguinte: os batecares, das castas altas, são os donos das terras. Os manducares, que são sudras, a casta mais humilde, e possivelmente descendentes dos dravidianos que habitavam Goa antes das invasões arianas, estão encarregados das lidas agrícolas. Devi e Seabra (1971, v. 1, p. 20) descrevem os manducares como "servos da gleba".

Apesar de ser um sistema muito antigo, podemos constatar no comentário abaixo do missionário francês Jean-Antoine Dubois o quanto aquele modelo de ocupação da terra se mantinha ainda vivo em pleno século XIX:

Ainda actualmente se observam outros factos que é indispensável ter presentes para formar uma concepção exacta da propriedade em terras de Goa. A fabricação de casas em terreno alheio é um costume geral que se encontra, sem excepção, em todas as aldeias. Com esse costume anda ligada uma ordem muito especial de relações entre o proprietário (batcará) e o colono (manducar), sem analogia no nosso systema de direito. Os manducares aproveitam-se das ólas, e de outras folhas, que lhes servem de combustivel, não pagam renda, vigiam o palmar, e prestam serviços por um salário em regra inferior ao do mercado. (DUBOIS, Description of the caracter, manners, and customs of the people of India. p. 477, apud AZEVEDO, 1980, p. 112)

O conto nada mais faz que encenar essa relação ancestral entre manducares e batecares, sendo que Shivá vem reafirmar essa ordem na defesa dos da casa grande. No mundo descrito pela autora, Goa vê-se livre dos seus antigos opressores coloniais sem, nesse processo, incorrer na destruição do sistema social indiano ali vigente.

Um momento do conto em particular demonstra o ar nacionalista que, por sinal, paira em vários contos da autora. Quando Vatsol e Suriá estão conversando, ouvem risos e vozes de homens que estão ali perto: "Alguns barbudos com turbantes, outros com boinas cor de pimenta seca" (DEVI \& SEABRA, 1971, p. 372), que Vatsol supõe serem soldados. Suriá, no entanto, observa que se trata de "homens de Bharat", isto é, "homens da Índia" (Bharat é o nome da Índia em hindi transcrito para o nosso alfabeto). Segue-se uma observação em estilo indireto: "Soldados eram aqueles", referindo-se aos portugueses. Os portugueses eram soldados porque vieram para Goa para oprimir os locais. Os indianos, por outro lado, são libertadores, que vieram ao socorro dos seus semelhantes. Na distinção que se faz sugere-se que Vatsol não precisa ter medo destes militares, pois são seus iguais.

É importante lembrar que o conto foi publicado em 1963, quando Goa já há dois anos deixara de ser uma colônia portuguesa. Desse modo, a indianidade do ambiente goês é sistematicamente marcada em todas as instâncias do conto: na ambientação do espaço rural e do sistema agrícola, na caracterização das personagens, que não apresentam qualquer traço europeu, na referência ao panteão de deuses hindus, como Indra, deus das 
tempestades, filho de Aditi com o sábio Kashyapa, ou de Shivá, que cumpre um papel importante no próprio desfecho da diegese. É verdade que também se faz menção à estrela Vênus (que representa a deusa do amor e da beleza) e aos Centauros (seres com cabeça de humano e corpo de cavalo), ambos da tradição greco-romana, mas é importante lembrar que a Índia nunca precisou dos portugueses para ter contato com essa tradição, que ali provavelmente já chegara antes das caravelas.

No entanto, o que mais marca a identidade local do conto é a sua linguagem. Emprega-se uma série de termos locais que não são explicados de forma alguma ao leitor. Expressões e palavras indianas estão distribuídas em todo o corpo do texto. Ali podemos encontrar: Devá! (Deus, Senhor); anhá-gunú (sons cacófatos), sopó (banco, geralmente de terra batida), bhatkar (batecar, escrito de maneira concanizante), anhã, anh (exclamação concani), zablés (plural de zabló, saco de cairo frito em malhas muito abertas para transporte de folhagem), zatrá (romaria, santuário), karm (destino), pimpôll (árvore sagrada), anupkâri (ingratos), tumim (vós, plural de tum), niró (seiva da palmeira), mara-mari (pancadaria), shi (outra exclamação comum do concani).

Além dessas palavras e expressões, aparecem também vocábulos que são pouco usuais, ao menos no português do Brasil, como, por exemplo: salangana, em vez de andorinha; panheira, em lugar de paineira; carrapito, para designar um punhado de cabelos atado no alto ou atrás da cabeça; fiada, para se referir a uma série de coisas ligadas, alinhadas; matula, para nomear gente ordinária, a gentalha; entre outras.

$\mathrm{O}$ fato é que esse vocabulário, somado às palavras e às expressões autóctones, faz com que o leitor não goês se coloque num lugar distanciado, como se fosse um estrangeiro em sua própria língua. Para o leitor de língua portuguesa em geral, estas inovações linguísticas criam uma forte sensação de estranhamento, um constante ruído na comunicação. Parece-nos claro que Maria Elsa da Rocha escreve num português formulado para um leitorado local, pois só quem fala concani pode ter uma compreensão plena do léxico ali empregado. Tal como Goa foi tomada aos portugueses, nos seus contos Rocha toma posse completa da língua do ex-colonizador. Assim, a língua portuguesa de Goa, tal como os brâmanes católicos do poema citado, aparece como plenamente indiana, apesar da sua história colonial. Soma-se, ainda, a isso, a dimensão lírica que Maria Elsa da Rocha imprime à sua prosa.

Também ele descera da barquinha e se pudera diante dela. Agora o verde já não era verde. Apenas a prata era prata. A noite estava de caminho, preguiçosa, sim, mas bruxenta. Tanto, que aos arbustos além já ela os tinha transformado em cabeças de centauros silenciosos, aguardando vítimas. (DEVI \& SEABRA, 1971, v. 2, p. 319)

Note-se como a percepção das cores se altera e a noite ganha vida, com características fantasmagóricas. Mais adiante ira dizer: "Vatsol fez sim com a cabeça e rompeu num choro, lúgubre, que trazia no seu caudal terroso esqueletos de árvores desenraizadas, de galhos quebrados, madeiros podres, côcos vãos...” (DEVI \& SEABRA, 1971, v. 2, p. 320)

O choro de Vatsol ganha materialidade na imagem de um rio caudaloso que tudo arrasta e destrói, seguindo sem rumo. Isso, que nos parece 
uma grande qualidade do texto de Maria Elsa da Rocha, pois rompe com a percepção realista do narrador e abre espaço para que a subjetividade da personagem seja explorada de forma bastante lírica, não é assim tomado por alguns de seus críticos.

Assim Devi e Seabra se referem à obra de Maria Elsa da Rocha:

A sua técnica assenta num processo de repetição de associações e emoções criadas vocabularmente com o objectivo de produzir ambientes psicológicos fortemente intensos. E raras vezes se preocupa em contar uma história. Quando o faz, como nos contos Vinte e Quatro, Zuleima ou Piquete, as suas soluções recorrem ao anedótico ou ao trágico lamecha. Mas na criação de ambientes há algo que falha e que só após a leitura por vezes se nota, pois os contos de Maria Elsa da Rocha esquecem-se com uma facilidade espantosa. Talvez isso seja culpa da excessiva acumulação de pormenores para a criação de ambientes, o que - como a floresta não deixando ver as árvores acaba por se sobrepor às próprias personagens. (DEVI \& SEABRA, 1971, v.1, p. 229)

Curiosamente, também Leopoldo da Rocha aponta na obra da escritora um estilo que peca pelo excesso: "Estilisticamente Elsa da Rocha talvez peque por falta de contenção no fluxo narrativo. No intuito de vincar bem os tiques ou reflexos psicológicos da sua personagem, Elsa recorre às vezes a imagens um tanto rebuscadas" (Rocha, 2010).

Não entendemos tais procedimentos como problemáticas. Pelo contrário, como dissemos, vemos aí um grande trunfo da escritora. A preocupação que Devi e Seabra revelam quanto a narrar uma história não nos parece pertinente, já que o propósito da contista é focar a subjetividade dos protagonistas Vatsol e Suriá. Ora estamos na pele de um, ora na pele do outro, vendo e sentindo como eles veem e sentem. Os fatos importam menos do que a forma como são percebidos por ambos. É disso que trata o conto: da subjetividade dessas personagens, com seus medos, inseguranças, desejos, expectativas.

O argumento de que são histórias/enredos que esquecemos com muita facilidade se relaciona com a própria proposta da autora, cuja técnica como contista pende mais para o lado poético do gênero do que para o romanesco. Ao final, ficamos mais com a experiência da atmosfera e das sensações sugeridas no conto do que com sua diegese. Não há um sentido moral evidente para a diegese. Há sentimento e sensação. A experiência da leitura aproxima-se da recepção de um poema simbolista, cuja realidade referencial temos dificuldade de precisar ou descrever, mas cujas sensações sabemos muito bem identificar.

O rebuscamento das imagens mencionado por Leopoldo da Rocha parece-nos que também tem a ver com a proposta estética de Maria Elsa da Rocha, na medida em que tal rebuscamento se faz na tentativa de desestabilizar a representação neorrealista da vida campesina goesa que se vê no romance O Signo da Ira de Orlando da Costa, por exemplo, ou nos contos de Vimala Devi, implacavelmente críticos para com os elites rurais de Goa. Se o tratamento dado à caracterização das condições sociais das personagens tem muito da estética neorrealista, essa estratégia de deses- 
tabilização, rompendo a expectativa criada com respeito a tal estética, faz com que a subjetividade das personagens ganhe maior força e se sobreponha à realidade imediata ali referenciada. Daí o conto ser muito mais sentimento subjetivo do que ação. O leitor é convidado a sentir empatia por Vatsol e Suriá, não a analisar criticamente as condições de vida da população "do prédio", isto é, da herdade.

No caso de "Shivá, brincando..., o sentimento de fidelidade e da abnegação em relação à família e aos batecares ao lado do sentimento amoroso jovial e ingênuo são os aspectos centrais do conto, sendo tais sentimentos o que fica de todo o percurso. Shivá atua em prol da manutenção de uma ordem social tradicional de hierarquia fixa, como já foi observado, mantendo a família de Vatsol unida, não deixando-a cair em desgraça e, assim, viabilizando seu casamento com Suriá sob os olhos benevolentes da família da "casa grande". O que está em jogo em todo o conto é a preservação do sistema de batecarato, que protege os fracos como Vatsol, possibilita o feliz desfecho do seu relacionamento com Suriá e permite uma certa ascensão social de Sauló, isto tudo, deduz-se, mantendo-se a posição social e econômica dos tradicionais donos da terra.

No entanto, nem só de subjetividade e sentimento vive o texto de Maria Elsa da Rocha. Há ainda outras chaves de leitura para esse conto que dizem respeito à situação política de Índia e de Goa na década de 1960. Após a independência do país, uma forte presença de ideais revolucionários, consolidados no Partido Comunista da Índia, fundado em 1920, passa a caracterizar a sociedade indiana e o conto não deixa de refletir isso. A ideia subjacente ao crescimento do comunismo na Índia, a de uma organização mais justa da partilha da terra, ganhou fôlego em Goa depois da democratização do território. As primeiras eleições livres foram ganhas não pelo Indian National Congress do libertador Nehru, como era de esperar, mas por uma formação chamada Maharastrawadi Gomtantak Party. Era um partido apoiado mormente por hindus de extratos sociais baixos, previamente discriminados sob o regime colonialista, mas constituindo a maioria da população goesa. Entre suas proposições estavam a integração do território goês ao estado vizinho de Maharastra (o que dava por findo a existência de Goa como tal), a valorização da cultura hindu de Goa (largamente desprezada pelo regime salazarista), assim como o desmantelamento da vantagem social que os católicos detinham na sociedade goesa sob o domínio português.

Quando Vatsol conta para Suriá o projeto encabeçado por seu irmão Sauló de assaltar a casa do batecar cristão, assim diz: “- Os do prédio vão assaltar a casa do Bhatkar hoje à noite. Dizem que lhes vão limpar tudo... Dizem que as terras já não thes pertencem, que tudo é nosso, nosso... nosso" (DEVI \& SEABRA, 1971, v. 2, p. 320). A fala de "os do prédio" se aproxima da postura de revolucionários que pretenderiam fazer justiça com as próprias mãos. Os indianos venceram os portugueses e agora, subentende-se, é a vez dos batecares católicos serem derrubados pelos manducares hindus. A própria instância coletiva da qual se origina tal fala, "os do prédio", "tudo é nosso, nosso... nosso", mesmo que vaga, deixa evidente que se trata de um grupo que falaria por toda a comunidade, na sua maioria hindu, a julgar pelas personagens que entram na narrativa, insatisfeitos com o sistema de batecarato, dispostos a uma ação de viés supostamente revolucionário. 
No entanto, gradativamente se evidencia o quão pouco revolucionária é aquela ação. Na visão dada pelo conto de Rocha, revela-se um oportunista sentimento de vingança direcionado aos batecares, fadado a redundar em prejuízos aos próprios manducares. Primeiramente porque se projeta um assalto e não uma tomada das terras e, sobretudo, porque o batecarato ao final acaba por vencer, ao cooptar para suas trincheiras o líder da ação supostamente revolucionária. O modo como Sauló é descrito no conto - homem balofo, que gosta de ostentação e que se envaidece com sua posição de mocadão - deixa clara o quanto sua ação nada tinha de verdadeiramente revolucionária. $\mathrm{O}$ conto deixa subentendido que a mesma ganância mal pensada caracteriza a atitude de "os do prédio", que nunca são retratados e que, sem explicação, nem aparecem aquando do assalto malogrado do Sauló.

Desse modo, no âmbito sociológico, o conto tematiza a instabilidade do sistema de batecarato, mas sobretudo sua manutenção a partir da reafirmação das tradições milenares, bastando lembrar a intervenção de Shivá e o fato de que Kaú, a avó de Vatsol e Sauló, que fora mulher e nora de mocadão, acaba por agradecer aos deuses o fato de Vatsol ganhar ao menos o status de irmã de mocadão. Mantinha-se assim a tradição de mocadãos na família.

Essa forma de tratar questões sociais e políticas a partir de uma perspetiva subjetivista e de um lirismo bastante acentuado pode ser encontrada também num poema de Maria Elsa da Rocha, do mesmo ano de 1963, intitulado "Esse teu sari", no qual o eu lírico enaltece a liberdade de Goa, mas logo recomenda que tome cuidado com o seu sári, pois ventos poderosos do Himalaia poderiam despedaçá-lo.

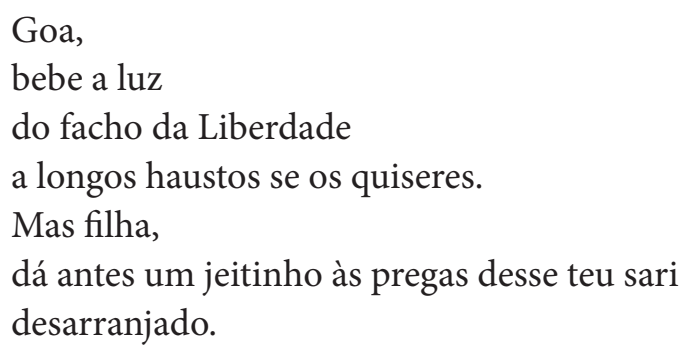


verde lentejoilando,

junto ao espelho do Mandovi,

empoa-te, filha,

na doirada poeira

que jorra

desse poente incandescente.

À noite,

se quiseres,

inda podes brincar,

alegre,

cosendo

ao sari de cacimba-húmida

a leitosa espuma

da cascata sempre a dar...

Mas menina, sê cautelosa!

manda a brisa, tua amiga,

dizer ao velho Himalaia

que cerre a cortina dos Gates,

que ventos insólitos

te podem arrancar

com fúria libidinosa,

gananciosa

pedaços

desse teu pobre manto... (ROCHA, 1963, p. 17)

Tal como o conto, o poema trabalha com fatos sociais a partir de imagens líricas. A liberdade política de Goa, conquistada dois anos antes, é tomada a partir da imagem de uma mulher vestida com um sári. O eu lírico recomenda que a mulher se preocupe com os ventos vindos do Himalaia, pois estes poderiam despedaçá-lo. Se lembrarmos que em 1962, um ano antes da publicação do poema, acontecia a Guerra Sino-Indiana pela disputas das montanhas do Himalaia e a fuga de Dalai Lama para a Índia, em razão da ocupação do Tibete pela China comunista, temos aqui uma leitura fortemente política dessa imagem lírica. Parece-nos provável que a elite latifundiária temia a expansão do comunismo sobre a Índia e a crescente exigência de uma reforma agrária em Goa ${ }^{1}$.

O conto e o poema questionam o uso da força contra as tradições em nome da ação revolucionária. Pretendem, sobretudo, denunciar os interesses sem vínculo real com o bem coletivo que fundamentariam algumas ações qualificadas como revolucionárias. A opção pelo subjetivismo e por imagens líricas para discutir questões tão concretas sugere a intenção da escritora de chamar a atenção e valorizar a dimensão humana da ordem social em oposição às ações políticas consideradas como exógenas em relação ao que seria o verdadeiro modo de ser indiano e goês.

Apesar de ser Vishnu o deus do panteão hindu que representa a preservação, Shivá cumpre no conto de Maria Elsa da Rocha esse papel. Essa preservação da tradição, no contexto goês, no entanto, tem o sentido de renovação. Depois da extirpação dos portugueses, acontece a transformação daquela antiga sociedade numa sociedade declaradamente indiana, mas sem o desmoronamento da hierarquia local, cuja elite até pode ser católica, mas cuja posição social tem suas raízes no período pré-português. 
A ideia de destruição, transformação e renovação ligada à imagem de Shivá na tradição indiana ganha então força na leitura do conto a partir do contexto histórico goês. Se Shivá brinca, assumindo a forma de uma serpente gigante, que é um dos elementos que acompanham sua representação, significando a superação da morte, temos nessa imagem a defesa divina, e portanto natural, da revitalização da organização social tradicional de Goa.

A ironia é que em 1964, um ano depois da publicação desse conto, o Maharashtrawadi Gomantak Party acabou por proclamar o Land to the Tiller Act, que, como o nome indica, outorgava a terra aos que a cultivam, o que minou irremediavelmente o sistema de batecarato. Assim "os do prédio" conseguiram na realidade pós-portuguesa o que o deus Shivá embargara no conto de Maria Elsa da Rocha.

\section{Notas}

1 Em abono desta idéia aparecem as seguintes linhas num poema coevo de Alfredo Bragança: "Eles foram.../Outros convidam/À escuridão/À escravidão/Profetas falsas/Para 'engolir'/nosso rincão/Cautela irmão! Cautela com amigos/À solda dos vizinhos! Avalanches dos estados inimigos/../É 'China’ dentro da Índia’ (Bragança, 1963, p. 2).

\section{REFERÊNCIAS BIBLIOGRÁFICAS}

AZEVEDO, Antonio Emílio d'Almeida. As comunidades de Goa - história das instituições antigas. Lisboa: Viúva Bertrand, 1980.

BRAGANÇA, Alfredo. “Goa viva, Goa livre”. A Vida, 15 dez. 1963, p. 2.

DALGADO, Sebastião Rodolfo. Dialecto indo-português de Goa. Rio de Janeiro: Livraria J. Leite, 1922.

DALGADO, Sebastião Rodolfo. Glossário luso-asiático. Coimbra: Universidade de Coimbra, 1919-1921, 2 v.

DEVI, Vimala, SEABRA, Manuel de. A literatura indo-portuguesa. Lisboa: Junta de Investigações do Ultramar, 1971, 2 v.

ROCHA, Leopoldo da. "Uma leitura do livro de contos Vivências partilhadas de Elsa da Rocha". In: Artes e Letras, 5 de jullho de 2010 - http:// lusogoanus.wordpress.com/2010/07/05/uma-leitura-do-livro-de-contos-vivencias-partilhadas-de-elsa-da-rocha/

ROCHA, Maria Elsa da. "Shivá, brincando". In: Vivências partilhadas. Panjim, Índia: Third Millennium, 2005.

ROCHA, Maria Elsa da. "Sâdhu”. A Vida, 5/01/1962, p. 2.

ROCHA, Maria Elsa da Rocha. "Esse teu sari”. A Vida, 15/09/1963, p.17.

(Recebido para publicação em 8/11/2010) 